\title{
A quantitative study of proton irradiation and UV photolysis of benzene in interstellar environments
}

\author{
R. Ruiterkamp ${ }^{1}$, Z. Peeters ${ }^{2}$, M. H. Moore ${ }^{3}$, R. L. Hudson ${ }^{4}$, and P. Ehrenfreund ${ }^{2}$ \\ 1 Leiden Observatory, PO Box 9513, 2300 RA Leiden, The Netherlands \\ e-mail: ruiterka@strw.leidenuniv.nl \\ 2 Astrobiology Laboratory, Leiden Institute of Chemistry, PO Box 9502, 2300 RA Leiden, The Netherlands \\ 3 NASA/Goddard Space Flight Center, Code 691, Greenbelt, Maryland 20771, USA \\ ${ }^{4}$ Department of Chemistry, Eckerd College, St. Petersburg, Florida 33733, USA
}

Received 29 September 2004 / Accepted 13 May 2005

\begin{abstract}
Benzene is an essential intermediate in the formation pathways of polycyclic aromatic hydrocarbons (PAHs) and carbon dust. Therefore, it is important to understand the interplay of formation and destruction in order to assess the lifetime of benzene in space. We performed UV photolysis and proton $(0.8 \mathrm{MeV})$ bombardment experiments on benzene $\left(\mathrm{C}_{6} \mathrm{H}_{6}\right)$ isolated in inert argon matrices and in oxygen-rich solid mixtures in the laboratory. The destruction of benzene in different chemical environments was measured for both methods of energetic processing. Additionally, we quantitatively determined the absorbed photon fraction in the sample layers when exposed to our UV lamp with actinometry. This enabled us to derive destruction cross sections for benzene for both UV photolysis and proton bombardment allowing us to compare these two ways of energetic processing. The laboratory data were extrapolated to different interstellar environments and we found that benzene is efficiently destroyed in diffuse interstellar clouds, but could survive dense cloud environments longer than the average lifetime of the cloud. Benzene is likely to survive in the dense parts of circumstellar envelopes around carbon-rich AGB stars but only in a very finite region where UV photons are attenuated.
\end{abstract}

Key words. ISM: molecules - ISM: abundances - ISM: clouds

\section{Introduction}

In the circumstellar envelopes of carbon-rich evolved stars a complex carbon chemistry occurs that is analogous to carbon soot formation in a candle flame or in industrial smoke stacks. Acetylene $\left(\mathrm{C}_{2} \mathrm{H}_{2}\right)$ polymerization is assumed to be the starting point for the development of hexagonal aromatic rings of carbon atoms. These aromatic rings probably react further to form large aromatic networks (Frenklach \& Feigelson 1989; Cherchneff et al. 1992). The most abundant complex organic molecules (not $\mathrm{CO}$ ) in the gas phase are polycyclic aromatic molecules (PAHs). These compounds are likely responsible for the unidentified infrared emission bands (UIBs) between 3 and $17 \mu \mathrm{m}$ (Hudgins \& Allamandola 1999a,b; Tielens et al. 1999), a spectroscopic signature observed in our and external galaxies. PAH ions are also suggested as the carriers of the Diffuse Interstellar absorption Bands (DIBs) that are found in the ultraviolet (UV) and visual ranges of the spectrum toward sources that probe the diffuse interstellar medium (see Herbig 1995, for a review). Laboratory simulations in combination with interstellar observations support the idea that the predominant fraction of carbon not locked up in CO is incorporated into solid macromolecular carbon (e.g. Pendleton \& Allamandola 2002) or amorphous and hydrogenated amorphous carbon (Pendleton \& Allamandola 2002; Dartois et al. 2004).
Benzene is the key molecule in the formation pathways of those complex carbon compounds in space. Benzene detection has been claimed in the Infrared Space Observatory (ISO) spectrum of the circumstellar envelope around CRL 618 (Cernicharo et al. 2001). The observed absorption band was restricted to the part of the circumstellar envelope where densities are high and UV radiation from the star and the surrounding interstellar medium are attenuated. The models of Woods et al. (2002) indicate rapid destruction of molecules in the circumstellar envelope of CRL 618 at a distance of $\sim 10^{16} \mathrm{~cm}$ from the central star.

Ices can be found in a range of astronomical environments such as covering silicate and carbon dust surfaces in dense interstellar clouds, on comets and on planetary surfaces (see Ehrenfreund et al. 2003). Ices in the interstellar medium (ISM) are dominated by $\mathrm{H}_{2} \mathrm{O}$ with contributions from $\mathrm{CO}, \mathrm{CO}_{2}$ and $\mathrm{CH}_{3} \mathrm{OH}$ and traces of molecules such as $\mathrm{CH}_{4}$ and $\mathrm{NH}_{3}$ (Whittet et al. 1996; Gibb et al. 2004). The composition of interstellar ice is governed by dynamic processes such as accretion/sublimation, barrier-less chemical reactions and energetic processing by UV and cosmic ray particles. The interplay between these mechanisms determines the composition and abundance of molecular species in ice layers (Johnson 1996; Greenberg et al. 2000; Sandford et al. 2001; Roser et al. 2001). 
Table 1. Observed wavenumbers and intrinsic strengths $(A)$ for benzene infrared bands in argon matrices.

\begin{tabular}{lllll}
\hline \hline Band $^{a}$ & $\begin{array}{l}\tilde{v}^{a} \\
\left(\mathrm{~cm}^{-1}\right)\end{array}$ & $\begin{array}{l}\tilde{v}^{b} \\
\left(\mathrm{~cm}^{-1}\right)\end{array}$ & $\begin{array}{l}A^{a} \\
\left(\mathrm{~cm} \mathrm{molec}^{-1}\right)\end{array}$ & $\begin{array}{l}\text { Assignment }^{a, c} \\
\end{array}$ \\
\hline$v_{20}, \mathrm{e}_{1 u}$ & 3103 & 3095 & & CH a.s. \\
$v_{1}+v_{6}+v_{8}, \mathrm{e}_{1 u}$ & 3080 & 3075 & \multirow{2}{*}{\} $1.1 \times 10^{-17}$} & comb. \\
$v_{8}+v_{19}, \mathrm{e}_{1 u}$ & 3048 & 3043 & & comb. \\
$v_{17}+v_{5}, \mathrm{e}_{1 u}$ & 1960 & 1957 & - & comb. \\
$v_{17}+v_{10}, \mathrm{e}_{1 u}$ & 1808 & 1812 & - & comb. \\
$v_{19}, \mathrm{e}_{1 u}$ & 1481 & 1481 & $4.7 \times 10^{-18}$ & CC a.s. \\
$v_{18}, \mathrm{e}_{1 u}$ & 1038 & 1038 & $2.5 \times 10^{-18}$ & CH i.p.b. \\
$v_{11}, \mathrm{a}_{2 u}$ & 674 & 678 & $2.0 \times 10^{-17}$ & CH o.p.b. \\
\hline
\end{tabular}

${ }^{a}$ Brown \& Person (1978).

${ }^{b}$ This study.

${ }^{c}$ Strazzulla \& Baratta (1991).

$\mathrm{CH}$ a.s. $=\mathrm{CH}$ aromatic stretching mode.

comb. = combination mode.

$\mathrm{CC}$ a.s. $=\mathrm{CC}$ aromatic stretching mode.

$\mathrm{CH}$ i.p.b. $=\mathrm{CH}$ in plane bending mode.

$\mathrm{CH}$ o.p.b. $=\mathrm{CH}$ out of plane bending mode.

Although not yet detected, benzene and PAHs could be present in dense molecular clouds where they are condensed into ice mantles on interstellar grains. UV photolysis and energetic proton bombardment experiments provide a means to determine the effects of different interstellar radiation environments. Matrix isolation spectroscopy in inert matrices is the most readily available technique to simulate gas phase behavior of interstellar molecules at diffuse and dense cloud temperatures. With this technique the stability of molecules under simulated interstellar conditions can be used as an upper limit for space conditions. Comparison of matrix isolation results to gas phase data shows a reasonable agreement (see Sect. 4, destruction in the interstellar gas may proceed at higher rates since intermolecular interactions are reduced). Previous studies of benzene in astronomical environments focussed on solid benzene layers that were bombarded with low energy ( $\mathrm{keV})$ helium ions (Strazzulla \& Baratta 1991).

In this paper we describe laboratory studies of benzene in a low temperature $\mathrm{Ar}$ matrix and in oxygen-rich matrices $\left(\mathrm{H}_{2} \mathrm{O}, \mathrm{CO}\right.$ and $\left.\mathrm{CO}_{2}\right)$ under simulated interstellar conditions. The quantitative effects of $\mathrm{UV}$ photolysis and $0.8 \mathrm{MeV}$ proton radiolysis on benzene in these solid matrices are compared. In Sect. 2 we briefly describe the laboratory set-ups and techniques used. In Sect. 3 we present the spectra and assignments of destruction fragments. In Sect. 4 the quantitative effects of UV photolysis and proton bombardment in binary solids are discussed and extrapolated in Sect. 5 for interstellar environments. We draw conclusions in Sect. 6.

\section{Experimental}

Two sets of experiments have been performed on each solid mixture in order to investigate the effects of proton irradiation and UV photolysis on benzene in $\mathrm{Ar}, \mathrm{H}_{2} \mathrm{O}, \mathrm{CO}$ and $\mathrm{CO}_{2}$ matrices. The proton irradiation experiments were performed at the NASA Goddard Space Flight Center while the UV photolysis experiments were performed at the Leiden Institute of Chemistry. The two experimental systems that were used are comparable. Both systems consist of a stainless steel high vacuum chamber with a suspended sample target that is attached to the cold end of a cryostat $(\sim 14 \mathrm{~K})$. The sample target can alternatively face a deposition system, an energy source (proton beam or hydrogen flow lamp) and a FTIR spectrometer.

The vapor of multiply distilled $\mathrm{C}_{6} \mathrm{H}_{6}$ or $\mathrm{H}_{2} \mathrm{O}$, and laboratory grade gases $\mathrm{Ar}, \mathrm{CO}$ and $\mathrm{CO}_{2}$ (Praxair 99.995\%) were mixed in a gas manifold and deposited onto the cold sample target. Condensation was typically at a rate of 2 to $5 \mu \mathrm{m} h^{-1}$. The ratio of benzene to matrix constituent was between 1:350 and 1:700 for the matrix isolation experiments in $\mathrm{Ar}, 1: 5$ for the $\mathrm{H}_{2} \mathrm{O}$ mixtures, 1:30 for the $\mathrm{CO}$ mixtures and 1:20 for the $\mathrm{CO}_{2}$ mixtures. Argon isolated sample thicknesses in $\mathrm{MeV}$ bombardment experiments were typically $\sim 10 \mu \mathrm{m}$ and the incident $0.8 \mathrm{MeV}$ protons had a projected range of $\sim 20 \mu \mathrm{m}$ (Northcliffe \& Shilling 1970). Sample thicknesses in oxygen rich ices were typically $1 \mu \mathrm{m}$. Stopping powers $\left(\mathrm{eV} \mathrm{cm}^{2} \mathrm{~g}^{-1}\right)$ for $0.8 \mathrm{MeV}$ protons in each experiment were calculated using the SRIM2003 software package by Biersack and Ziegler (Biersack \& Haggmark 1980; Ziegler 1977). We obtained 170.2, 274.1, 245.7 and 241.1 $\mathrm{MeV} \mathrm{cm}^{2} \mathrm{~g}^{-1}$ for pure $\mathrm{Ar}, \mathrm{H}_{2} \mathrm{O}, \mathrm{CO}$ and $\mathrm{CO}_{2}$ solid matrices, respectively and $307.1 \mathrm{MeV} \mathrm{cm}^{2} \mathrm{~g}^{-1}$ for pure solid $\mathrm{C}_{6} \mathrm{H}_{6}$. UV photolysis experiments were performed in matrices less than $\sim 0.1 \mu \mathrm{m}$ thick for the oxygen rich matrices and $1 \mu \mathrm{m}$ for matrix isolation experiments in Ar, and are considered optically thin for the radiation wavelengths used. Sample preparation techniques and irradiation procedures used in proton bombardment experiments are described in Hudson \& Moore (1995); Moore \& Hudson (1998) and Gerakines et al. (2000). UV irradiation experiments were performed at a system pressure of $\sim 5 \times 10^{-8}$ mbar while the proton irradiation experiments were performed at a system pressure of $\sim 1 \times 10^{-7}$ mbar.

Protons were accelerated with a Van de Graaf generator located at the Cosmic Ice Laboratory at NASA Goddard Space Flight Center that delivered protons with an energy of $0.8 \mathrm{MeV}$ to the sample. To deliver high energy photons to the samples, a microwave-powered hydrogen flow lamp (Opthos Instruments, similar to the lamp in Gerakines et al. 2000) was mounted on the setup. The lamp flux at a forward/reflected power ratio of $100 / 6$ was $1.1 \times 10^{14}$ photons $\mathrm{cm}^{-2} \mathrm{~s}^{-1}$ for the oxygen rich matrices and $4.5 \times 10^{14}$ photons $\mathrm{cm}^{-2} \mathrm{~s}^{-1}$ for the matrix isolation experiments in Ar. These values were derived from the conversion of $\mathrm{O}_{2}$ to $\mathrm{O}_{3}$ when irradiated with UV photons (actinometry). Details on this calibration method can be found in Cottin et al. (2003). The average photon energy over the entire lamp spectrum is calculated to be $7.41 \pm 0.23 \mathrm{eV}$. The total flux of $\mathrm{Ly}_{\alpha}$ emission is at most 5\% of the total energy between 100 and $200 \mathrm{~nm}$ (Cottin et al. 2003).

In the proton bombardment experiments we used reflection infrared spectroscopy on an ice covered aluminium sample mirror suspended in a FTIR spectrometer (Mattson, spectral range $4000-400 \mathrm{~cm}^{-1}$ and resolution $4 \mathrm{~cm}^{-1}$ ). In the UV photolysis 


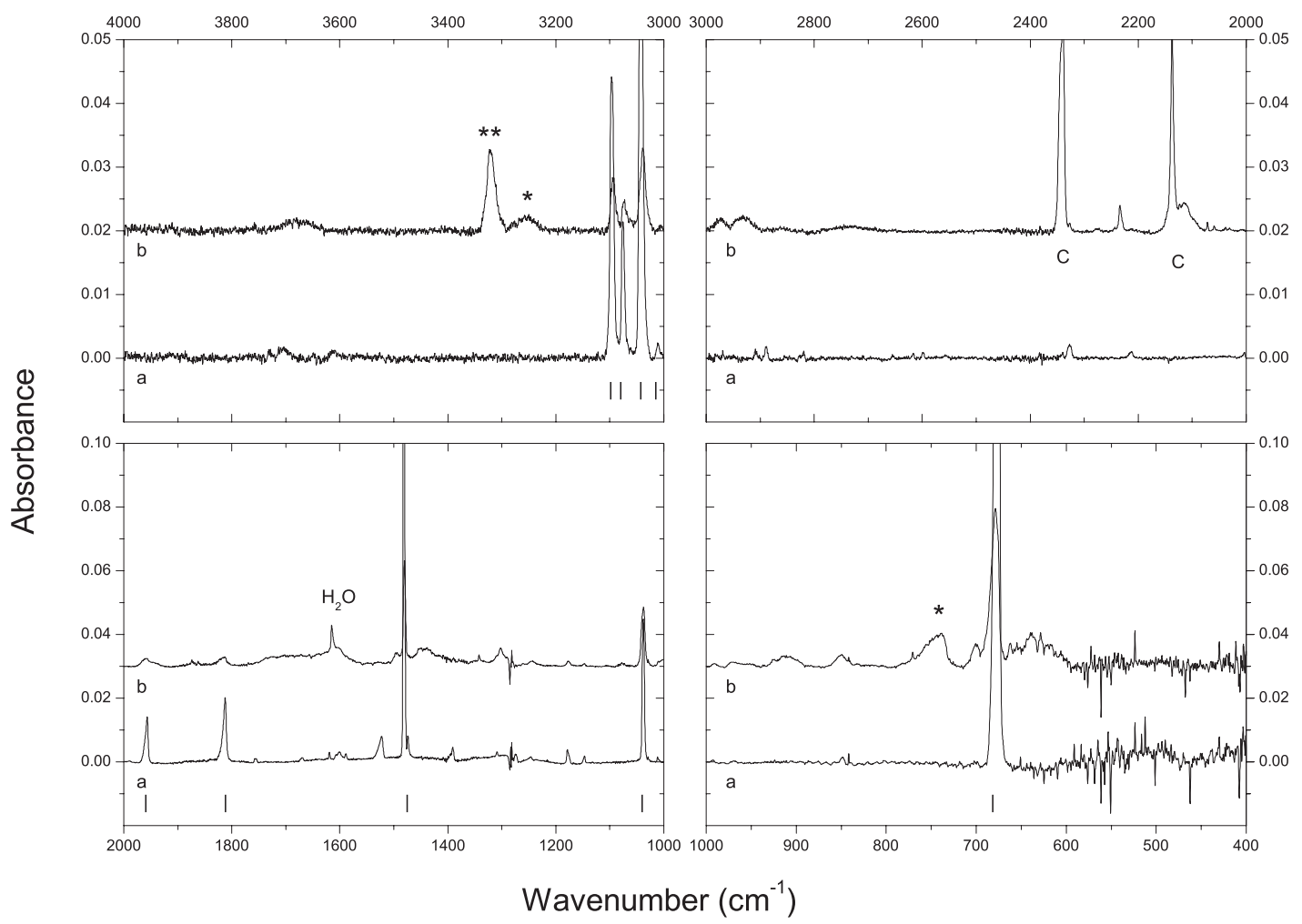

Fig. 1. IR spectrum of benzene isolated in argon (1:500) in the range 4000-2000 $\mathrm{cm}^{-1}$ (top panels) and $2000-400 \mathrm{~cm}^{-1}$ (bottom panels). Trace a) depicts the spectrum of $\mathrm{C}_{6} \mathrm{H}_{6} / \mathrm{Ar}$ before irradiation and trace b) shows the spectrum after proton bombardment to a total dose of $\sim 10 \mathrm{eV}$ molecule ${ }^{-1}$. Vertical dashes indicate the position of benzene spectral features. A single asterisk indicates a transition of acetylene and a double asterisk indicates matrix isolated methylacetylene. Contaminations from the vacuum chamber are indicated by a " $\mathrm{C}$ " (indicated are $\mathrm{CO}_{2}$ and $\mathrm{CO}$ as contaminants after proton bombardment).

experiments we used transmission spectroscopy of a thin film of ice on a CsI sample window suspended in a Biorad FTIR spectrometer with spectral range $4000-400 \mathrm{~cm}^{-1}$ at resolution $1 \mathrm{~cm}^{-1}$ (Peeters et al. 2003).

\section{Results}

\subsection{Proton bombardment and UV photolysis of solid $\mathrm{C}_{6} \mathrm{H}_{6}$}

We exposed layers of pure solid benzene to $0.8 \mathrm{MeV}$ protons and UV photolysis. Vibrational assignments before and after exposure were obtained using the work of Strazzulla \& Baratta (1991) and references therein (see Table 1). Identical products were observed in proton bombardment and UV photolysis, although due to the thin sample layer in UV photolysis experiments not all products could be observed. Our results are used for quantitative analysis (see Sect. 4) and we refer to Strazzulla \& Baratta (1991) for detailed spectra.

\subsection{Proton bombardment and UV photolysis of $\mathrm{C}_{6} \mathrm{H}_{6}$ matrix isolated in $\mathrm{Ar}$}

A frozen layer of $\mathrm{a}_{6} \mathrm{H}_{6} / \mathrm{Ar}$ mixture with a ratio of $\sim 1: 500$ was subjected to irradiation with high energy $(0.8 \mathrm{MeV})$ protons and the destruction of the benzene molecule was monitored by infrared spectroscopy. For band identification, we compared our spectra to matrix isolated benzene spectra from Brown $\&$ Person (1978) and pure benzene spectra from Strazzulla \& Baratta (1991). Most of the newly appearing bands could be identified although some bands appear slightly shifted between pure and isolated benzene, possibly due to matrix effects. Figure 1 shows the full mid-IR spectrum of benzene isolated in an argon matrix before and after proton irradiation. Figure 2 shows enlargements of two regions of spectra of proton irradiated benzene isolated in argon. Figure 2 also includes the spectrum of acetylene for comparison.

Table 2 lists the new bands (and their assignments) that appear after proton bombardment and UV photolysis of benzene isolated in an argon matrix, compared to literature values for $3 \mathrm{keV}$ proton bombardment of frozen pure benzene layers. The features that appear at $2071 \mathrm{~cm}^{-1}$ in UV photolysis and $1904 \mathrm{~cm}^{-1}$ in proton bombardment experiments could not be assigned. Features at 2350 and $2140 \mathrm{~cm}^{-1}$, peaks assigned to $\mathrm{CO}_{2}$ and $\mathrm{CO}$, respectively are a result of contaminants in the setup. $\mathrm{CO}_{2}$ and $\mathrm{CO}$ form through reaction of $\mathrm{H}_{2} \mathrm{O}$ dissociation products such as $\mathrm{OH}$ radicals with contaminants from the vacuum chamber. The long experiment run times (up to $11 \mathrm{~h}$ ) explain the large quantities of $\mathrm{CO}$ and $\mathrm{CO}_{2}$ observed.

\subsubsection{The case of acetylene}

Since benzene can be formed through the polymerization of three acetylene molecules, it is expected that decomposition of 
Table 2. Observed new spectral bands after $\mathrm{keV} \mathrm{He}^{+}$bombardment of pure benzene (Strazzulla \& Baratta 1991, Col. A), MeV p $\mathrm{p}^{+} \mathrm{UV}$ irradiation of pure benzene in this study (Col. B) and $\mathrm{MeV} \mathrm{p}^{+} / \mathrm{UV}$ processing of benzene isolated in argon matrices (Col. C). Note that the same destruction products appear when matrix isolated benzene is exposed to protons or UV (only the intensity of appearing bands differs according to the method of processing).

\begin{tabular}{|c|c|c|c|}
\hline $\begin{array}{c}\text { A } \\
\text { pure } \mathrm{C}_{6} \mathrm{H}_{6} \\
\mathrm{~cm}^{-1}(\mu \mathrm{m}) \\
\end{array}$ & $\begin{array}{c}\text { B } \\
\text { pure } \mathrm{C}_{6} \mathrm{H}_{6} \\
\mathrm{~cm}^{-1}(\mu \mathrm{m}) \\
\end{array}$ & $\begin{array}{c}\mathrm{C} \\
\text { isolated } \mathrm{C}_{6} \mathrm{H}_{6} / \mathrm{Ar} \\
\mathrm{cm}^{-1}(\mu \mathrm{m}) \\
\end{array}$ & Assignment \\
\hline- & - & $3321(3.01)$ & MIS $\mathrm{HC}_{2} \mathrm{CH}_{3}$ \\
\hline- & - & $3302(3.03)$ & MIS $\mathrm{C}_{2} \mathrm{H}_{2}$ \\
\hline $3288(3.04)$ & $3278(3.05)$ & - & $\mathrm{C}_{2} \mathrm{H}_{2}$ aggregates \\
\hline $3232(3.09)$ & $3232(3.09)$ & $3245(3.08)$ & $\mathrm{C}_{2} \mathrm{H}_{2}$ \\
\hline $2888(3.46)$ & $2888(3.46)$ & $2888(3.46)$ & C-H aliph str \\
\hline $2824(3.54)$ & $2818(3.55)$ & $2820(3.55)$ & C-H aliph str \\
\hline $2116(4.73)$ & $2107(4.75)$ & $2124(4.71)$ & $\mathrm{C} \equiv \mathrm{C}$ str monosubst $\mathrm{C}_{2} \mathrm{H}_{2}$ \\
\hline - & - & $2071(4.83)$ & $?$ \\
\hline $1952(5.12)$ & $1956(5.11)$ & & subst $\mathrm{C}_{6} \mathrm{H}_{6}$ \\
\hline- & $1904(5.30)$ & - & $?$ \\
\hline $1604(6.23)$ & $1604(6.23)$ & - & $\mathrm{C}=\mathrm{C}$ str subst $\mathrm{C}_{6} \mathrm{H}_{6}$ \\
\hline $1556(6.43)$ & $1522(6.57)$ & - & $\mathrm{C}=\mathrm{C}$ str subst $\mathrm{C}_{6} \mathrm{H}_{6}$ \\
\hline $1414(7.07)$ & - & $1391(7.19)$ & comb band $\mathrm{C}_{2} \mathrm{H}_{2}$ \\
\hline $1180(8.47)$ & - & $1180(8.47)$ & $\mathrm{C}-\mathrm{H}$ ip bend $\mathrm{C}_{6} \mathrm{H}_{6}$ \\
\hline $1152(9.76)$ & - & $1146(8.73)$ & $\mathrm{C}-\mathrm{H}$ ip bend $\mathrm{C}_{6} \mathrm{H}_{6}$ \\
\hline $1080(9.26)$ & $1075(9.29)$ & $1076(9.29)$ & C-H ip bend $\mathrm{C}_{6} \mathrm{H}_{6}$ \\
\hline $916(10.92)$ & $909(11.00)$ & $912(10.97)$ & C-H op bend $\mathrm{C}_{2} \mathrm{H}_{2}$ \\
\hline $770-730(12.99-13.70)$ & $770(12.99)$ & - & $\mathrm{C}_{6} \mathrm{H}_{5}$ ? \\
\hline $754(13.26)$ & 758 13.19) & $740(1351)$ & $\mathrm{C}-\mathrm{H}$ op bend $\mathrm{C}_{2} \mathrm{H}_{2}$ \\
\hline $700(14.29)$ & $700(14.29)$ & $700(14.29)$ & $\mathrm{C}-\mathrm{H}$ op bend $\mathrm{C}_{6} \mathrm{H}_{6}$ \\
\hline $648(15.43)$ & $631(15.85)$ & $637(15.70)$ & C-H op bend $\mathrm{C}_{2} \mathrm{H}_{2}$ \\
\hline $\begin{array}{l}\text { MIS = matrix isolated. } \\
\text { aliph = aliphatic. } \\
\text { asymm = asymmetric. } \\
\text { bend = bending vibration. }\end{array}$ & & $\begin{array}{l}\text { ip }=\text { in plane. } \\
\text { op }=\text { out of plane. } \\
\text { str }=\text { stretching vi } \\
\text { subst }=\text { substitutec }\end{array}$ & on. \\
\hline
\end{tabular}
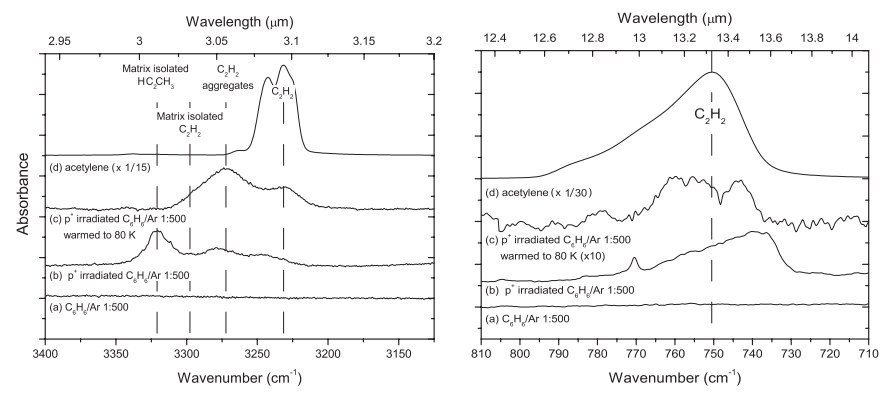

Fig. 2. Identification of acetylene infrared bands in the $3400-3100 \mathrm{~cm}^{-1}$ and $810-710 \mathrm{~cm}^{-1}$ range after proton bombardment of benzene isolated in argon (1:500). From bottom to top, traces show a) an unirradiated $\mathrm{C}_{6} \mathrm{H}_{6} / \mathrm{Ar}$ sample with a ratio of 1:500 at $\sim 14 \mathrm{~K}$, b) the same sample irradiated to a dose of $\sim 10 \mathrm{eV}^{\text {molecule }}{ }^{-1}$, c) the same proton irradiated sample warmed to $80 \mathrm{~K}$ (to remove all argon) that shows the disappearance of the band at $3321 \mathrm{~cm}^{-1}$ and $3302 \mathrm{~cm}^{-1}$ attributed to matrix-isolated methylacetylene and acetylene, respectively, and d) unirradiated pure (not isolated) acetylene at $\sim 14 \mathrm{~K}$. Some spectra were scaled with the factor given in parentheses.

benzene yields acetylene. Nevertheless, we considered many other small molecules in our search for radiolytic and photolytic products. Among the investigated compounds were molecules, radicals and ions such as methane, ethane, propane, ethylene, phenyl radical, benzene ions and propylene.

Assignments by Strazzulla \& Baratta (1991) were used to identify most of the new bands after energetic processing. However, some differences were found (see Table 2). The weak band at $3302 \mathrm{~cm}^{-1}$ could be assigned to matrix isolated acetylene by comparing to literature values (George et al. 2003). The band at $3321 \mathrm{~cm}^{-1}$ could be assigned to matrix isolated methylacetylene (Jacox \& Milligan 1974, $\mathrm{HC}_{2} \mathrm{CH}_{3}$ ). Upon warm up of the irradiated sample to above the sublimation temperature of argon $(\sim 45 \mathrm{~K})$ the isolated methylacetylene feature at $3321 \mathrm{~cm}^{-1}$ disappeared and the bands around $3278 \mathrm{~cm}^{-1}$ and $3245 \mathrm{~cm}^{-1}$ increased in intensity due to sublimation of the matrix. Strazzulla \& Baratta (1991) assigned the band around $3278 \mathrm{~cm}^{-1}$ to monosubstituted acetylene. Since this band increases upon warm up to $80 \mathrm{~K}$ we think that this band can be tentatively assigned to $\mathrm{C}_{2} \mathrm{H}_{2}$ aggregates which could also include complexes between $\mathrm{HC}_{2} \mathrm{CH}_{3}$ and $\mathrm{C}_{2} \mathrm{H}_{2}$. However, these experiments were not specifically aimed to give a definitive assignment of the bands that appear after energetic processing and future work is needed to investigate these details. 

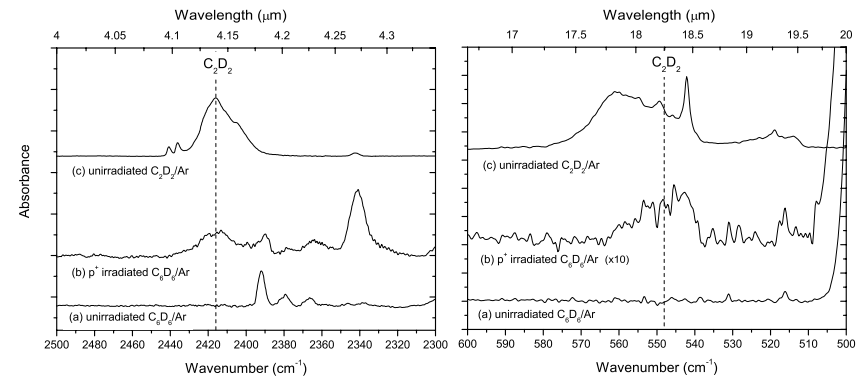

Fig. 3. IR spectra of $\mathrm{a}_{6} \mathrm{D}_{6} / \mathrm{Ar}$ samples after proton bombardment between 2500-2300 and 600-500 $\mathrm{cm}^{-1}$. Trace a) shows an unirradiated $\mathrm{C}_{6} \mathrm{D}_{6} / \mathrm{Ar}$ sample with a ratio of 1:500 at $\sim 14 \mathrm{~K}$, b) the same sample, after irradiation with protons to a total dose of $10 \mathrm{eV}$ molecule ${ }^{-1}$ and c) an unirradiated $\mathrm{C}_{2} \mathrm{D}_{2} / \mathrm{Ar}$ sample with a ratio of $1: 100$ at $\sim 14 \mathrm{~K}$. The figure shows that upon proton bombardment of $\mathrm{C}_{6} \mathrm{D}_{6}$ new bands appear that can be assigned to $\mathrm{C}_{2} \mathrm{D}_{2}$, confirming the formation of acetylene by energetic processing of $\mathrm{C}_{6} \mathrm{H}_{6}$. $\mathrm{CO}_{2}$ is observed at $2340 \mathrm{~cm}^{-1}$ as a radiolysis contaminant.

The right panel of Fig. 2 shows the spectral region including the $v_{5}$ mode of acetylene between $730-770 \mathrm{~cm}^{-1}$. Unfortunately transitions of dehydrogenated benzene (i.e. $\mathrm{C}_{6} \mathrm{H}_{5}, \mathrm{C}_{6} \mathrm{H}_{4}, \ldots$ ) fall in this region (Strazzulla \& Baratta 1991) making a clear identification of $\mathrm{C}_{2} \mathrm{H}_{2}$ impossible. Therefore, we can not use this region to determine the column density of $\mathrm{C}_{2} \mathrm{H}_{2}$ in our experiments.

However, the production of acetylene can further be deduced from a comparison between the radiolysis products of matrix isolated $\mathrm{C}_{6} \mathrm{D}_{6}$ and matrix isolated $\mathrm{C}_{2} \mathrm{D}_{2}$. From Fig. 3 we see that the bands that appear at 2420 and $560 \mathrm{~cm}^{-1}$ in the proton bombardment experiments of a $\mathrm{C}_{6} \mathrm{D}_{6} / \mathrm{Ar}$ (1:500) sample (trace b), are well reproduced by a $\mathrm{C}_{2} \mathrm{D}_{2} / \mathrm{Ar}$ sample mixture (trace $\mathrm{c}$ ). Figure 3 shows that upon proton bombardment of $\mathrm{C}_{6} \mathrm{D}_{6}$ new bands appear that can be assigned to $\mathrm{C}_{2} \mathrm{D}_{2}$ confirming the formation of acetylene from $\mathrm{C}_{6} \mathrm{H}_{6}$ destruction. No attempt is made to calculate formation cross sections for acetylene in these experiments.

\subsection{Benzene in oxygen rich ices}

\subsubsection{Binary solids: $\mathrm{C}_{6} \mathrm{H}_{6} / \mathrm{H}_{2} \mathrm{O}$}

In Fig. 4 we show the spectrum of a $\mathrm{C}_{6} \mathrm{H}_{6} / \mathrm{H}_{2} \mathrm{O}$ mixture before and after proton bombardment. We compare the quantitative results for photolysis and radiolysis of $\mathrm{C}_{6} \mathrm{H}_{6} / \mathrm{H}_{2} \mathrm{O}$ (1:5) samples in Sect. 4. After irradiation new bands appeared. Table 3 lists the wavenumber $\left(\mathrm{cm}^{-1}\right)$ and wavelength $(\mu \mathrm{m})$ of the new bands as well as their possible assignment. During proton bombardment we found new bands around 763 and $746 \mathrm{~cm}^{-1}$ that were not seen after UV photolysis.

Due to the strong UV absorption of $\mathrm{H}_{2} \mathrm{O}$, only thin sample layers $(<0.1 \mu \mathrm{m})$ could be used to allow full penetration of the UV through the sample. Therefore, in UV irradiated solid $\mathrm{H}_{2} \mathrm{O}$ the photoproducts are produced at much smaller abundances than in proton bombarded solid $\mathrm{H}_{2} \mathrm{O}$. By comparing to literature values from Moore \& Hudson (2000) we have assigned the weak band at $2870 \mathrm{~cm}^{-1}$ to $\mathrm{H}_{2} \mathrm{O}_{2}$. Samples were bombarded with a total dose of $\sim 25 \mathrm{eV}$ molecule ${ }^{-1}$.

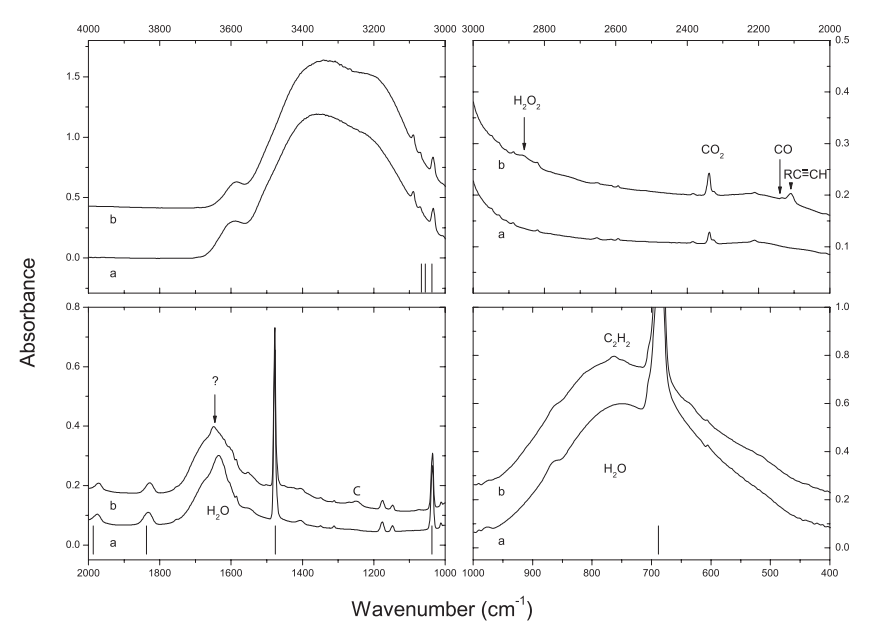

Fig. 4. New bands that appeared in solid $\mathrm{C}_{6} \mathrm{H}_{6} / \mathrm{H}_{2} \mathrm{O}$ (1:5) after proton irradiation. Trace a) shows the spectrum before radiolysis and trace b) depicts the same spectral region after radiolysis to a dose of $\sim 25 \mathrm{eV}$ molecule ${ }^{-1}$. New bands are blended with the strong $\mathrm{H}_{2} \mathrm{O}$ absorption bands and are not clearly visible. See Table 3. Benzene features are marked with vertical tick marks and contamination from the vacuum system is marked with " $\mathrm{C}$ ".

Table 3. Observed new features after proton and UV irradiation of solid $\mathrm{C}_{6} \mathrm{H}_{6} / \mathrm{H}_{2} \mathrm{O}$ (1:5) samples. Figure 4 shows the spectra of solid $\mathrm{C}_{6} \mathrm{H}_{6} / \mathrm{H}_{2} \mathrm{O}$ before and after proton irradiation. Infrared modes of $\mathrm{H}_{2} \mathrm{O}$ could obscure bands of some photoproducts. Additionally, due to the thin sample layers $(<0.1 \mu \mathrm{m}) \mathrm{UV}$ irradiated samples show benzene photoproducts only at very small abundances.

\begin{tabular}{lllll}
\hline \hline \multicolumn{3}{c}{ Observed transition } & Assignment \\
$\mathrm{p}^{+}$ & \multicolumn{2}{c}{$\mathrm{UV}$} & \\
$\left(\mathrm{cm}^{-1}\right)$ & $(\mu \mathrm{m})$ & $\left(\mathrm{cm}^{-1}\right)$ & $(\mu \mathrm{m})$ & \\
\hline 2870 & 3.48 & & & $\mathrm{H}_{2} \mathrm{O}_{2}{ }^{*}$ \\
2340 & 4.27 & 2340 & 4.27 & $\mathrm{CO}_{2}$ \\
2140 & 4.67 & 2140 & 4.67 & $\mathrm{CO}$ \\
2110 & 4.53 & & & $\mathrm{C} \equiv \mathrm{C}$ str monosubst $\mathrm{C}_{2} \mathrm{H}_{2}$ \\
1653 & 6.05 & & & $?$ \\
763 & 13.11 & & & $\mathrm{C}_{2} \mathrm{H}_{2}$ \\
746 & 13.40 & & $\mathrm{C}_{2} \mathrm{H}_{2}$ \\
\hline
\end{tabular}

Also observed in UV photolysis of pure solid $\mathrm{H}_{2} \mathrm{O}$ (Gerakines et al. 1996).

During UV photolysis of solid $\mathrm{H}_{2} \mathrm{O}$, molecules are dissociated to form $\mathrm{H}_{2} \mathrm{O}_{2}$, and $\mathrm{H}$. and $\mathrm{OH}$. radicals. During proton bombardment of water ice apart from $\mathrm{H} \cdot$ and $\mathrm{OH} \cdot$ radicals, $\mathrm{OH}^{-}$and $\mathrm{H}_{3} \mathrm{O}^{+}$ions could be formed. These irradiation products can subsequently react with other species in the matrix. Proton-irradiation of benzene in water ice could then yield such species as phenol $\left(\mathrm{C}_{6} \mathrm{H}_{5} \mathrm{OH}\right)$. However, we did not detect phenol. Production of $\mathrm{CO}_{2}$ and $\mathrm{CO}$ features upon energetic processing in these matrices are due to the oxidation of benzene fragments.

\subsection{Binary solids: $\mathrm{C}_{6} \mathrm{H}_{6} / \mathrm{CO}$}

Proton irradiation of solid $\mathrm{C}_{6} \mathrm{H}_{6} / \mathrm{CO}(1: 30)$ samples resulted in the destruction of benzene and the formation of new bands (see 


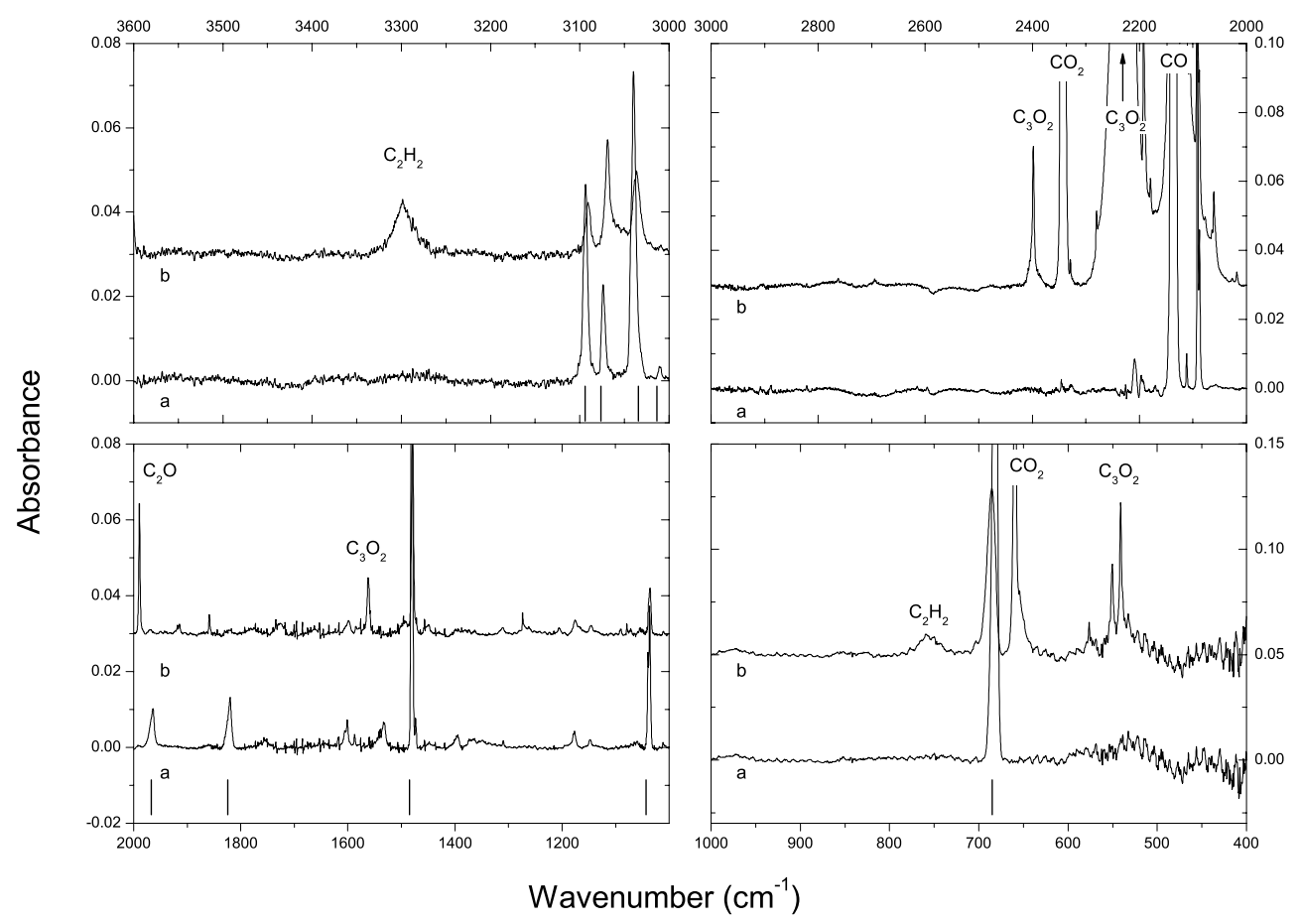

Fig. 5. The spectra of solid $\mathrm{C}_{6} \mathrm{H}_{6} / \mathrm{CO}(1: 30)$ before and after proton irradiation. Trace a) depicts the spectral region before irradiation, while trace b) shows the spectrum after irradiation to a total dose of $\sim 15 \mathrm{eV}$ molecule ${ }^{-1}$. Bands and possible assignments are listed in Table 4 . Benzene features are marked with vertical tick marks.

Fig. 5). The observed bands that appeared after energetic processing and their assignments are listed in Table 4. During proton irradiation new bands appeared that were not seen during UV photolysis. Apart from the bands due to $\mathrm{CO}_{2}$, new bands appeared at 2398, 2242, 1562, 960, 550 and $541 \mathrm{~cm}^{-1}$. We look at the quantitative difference between photolysis and radiolysis of $\mathrm{C}_{6} \mathrm{H}_{6} / \mathrm{CO}$ solids in Sect. 4.

Due to the high dissociation energy $(11 \mathrm{eV})$ of $\mathrm{CO}$ no single-step photodestruction can occur during UV photolysis. However, formation of activated $\mathrm{CO}$ molecules can lead to subsequent chemical reactions and may yield a small amount of $\mathrm{CO}_{2}$ during UV photolysis (Okabe 1978). We see a number of UV photoproduct bands that are not seen after proton irradiation and vice versa. Bands that appeared solely during UV photolysis are located at 1585, 1525, 832, 744 and $580 \mathrm{~cm}^{-1}$ and are assigned in Table 4 . New products are primarily $\mathrm{CO}_{2}$ and $\mathrm{C}_{3} \mathrm{O}_{2}$.

\subsection{Binary solids: $\mathrm{C}_{6} \mathrm{H}_{6} / \mathrm{CO}_{2}$}

We exposed solid $\mathrm{C}_{6} \mathrm{H}_{6} / \mathrm{CO}_{2}$ (1:20) samples to UV irradiation and proton bombardment. New features that appeared after irradiation of $\mathrm{C}_{6} \mathrm{H}_{6} / \mathrm{CO}_{2}$ samples are given in Table 5 as well as possible assignments. Energetic processing of pure solid $\mathrm{CO}_{2}$ yielded $\mathrm{CO}$ in both $\mathrm{UV}$ photolysis and radiolysis experiments. Figure 6 shows a comparison between the deposited sample before and after proton irradiation to a total dose of $\sim 15 \mathrm{eV}$ molecule ${ }^{-1}$. We look at the quantitative results of photolysis and radiolysis of $\mathrm{C}_{6} \mathrm{H}_{6} / \mathrm{CO}_{2}$ samples in Sect. 4 .

During proton bombardment of $\mathrm{C}_{6} \mathrm{H}_{6} / \mathrm{CO}_{2}$ samples new bands appeared at $3298,3252,1880$ and $763 \mathrm{~cm}^{-1}$ that have no counterpart in UV photolysis experiments. New bands around 3298 and $3252 \mathrm{~cm}^{-1}$ could possibly be assigned to acetylene in a $\mathrm{CO}_{2}$ environment.

\section{Discussion}

In the quantitative analysis that is described in this section only low proton and photon fluences are used and we may assume optically thin sample layers in all experiments.

For calculation of the destruction cross section of benzene isolated in an Ar matrix we have used the broad $\mathrm{C}-\mathrm{H}$ stretching vibration around $3103 \mathrm{~cm}^{-1}$, the strong aromatic $\mathrm{C}=\mathrm{C}$ stretching vibration at $1481 \mathrm{~cm}^{-1}$ and the $\mathrm{C}-\mathrm{H}$ in plane bending vibration at $1038 \mathrm{~cm}^{-1}$. All oxygen rich matrices $\left(\mathrm{H}_{2} \mathrm{O}, \mathrm{CO}_{2}\right.$ and $\mathrm{CO}$ ) used show strong absorptions in the infrared and therefore not all infrared active benzene bands could be measured. This especially applies to the broad bands of water. We have used the 1481, 1040 and $688 \mathrm{~cm}^{-1}$ bands of benzene in all quantitative analyses when not obscured by absorption bands of the matrix material.

\subsection{Energy dose delivered by photolysis and proton bombardment}

\subsubsection{Photolysis}

The energy absorbed by a benzene molecule in our UV irradiation experiments can be expressed as a dose in units of $\left[\mathrm{eV}\right.$ molecule $\left.\mathrm{e}^{-1}\right]$ by:

$D_{\mathrm{UV}}=\frac{\left\langle E_{h v}\right\rangle \Phi_{\mathrm{abs}} t}{N_{0}}$ 
Table 4. Observed new features after proton and UV irradiation of solid $\mathrm{C}_{6} \mathrm{H}_{6} / \mathrm{CO}(1: 30)$ samples. Figure 5 shows the spectra of solid $\mathrm{C}_{6} \mathrm{H}_{6} / \mathrm{CO}$ before and after proton irradiation. UV irradiation of $\mathrm{CO}$ does not photodissociate the $\mathrm{CO}$ molecule directly and fewer photoproduct bands appeared in these experiments compared to proton bombarded $\mathrm{C}_{6} \mathrm{H}_{6} / \mathrm{CO}$.

\begin{tabular}{|c|c|c|c|c|}
\hline \multicolumn{4}{|c|}{ Observed transition } & \multirow[t]{3}{*}{ Assignment } \\
\hline \multicolumn{2}{|c|}{$\mathrm{p}^{+}$} & \multicolumn{2}{|c|}{ UV } & \\
\hline$\left(\mathrm{cm}^{-1}\right)$ & $(\mu \mathrm{m})$ & $\left(\mathrm{cm}^{-1}\right)$ & $(\mu \mathrm{m})$ & \\
\hline 3741 & 2.67 & & & $\mathrm{CO}_{2}^{*}$ \\
\hline 3597 & 2.78 & & & $\mathrm{CO}_{2}^{*}$ \\
\hline 3297 & 3.03 & & & $\mathrm{C}_{2} \mathrm{H}_{2}$, substituted \\
\hline 3252 & 3.08 & & & $\mathrm{C}_{2} \mathrm{H}_{2}$ \\
\hline 2398 & 4.17 & & & $\mathrm{C}_{3} \mathrm{O}_{2}^{*}$ \\
\hline 2340 & 4.27 & 2340 & 4.27 & $\mathrm{CO}_{2}^{*}$ \\
\hline 2242 & 4.46 & & & $\mathrm{C}_{3} \mathrm{O}_{2}^{*}$ \\
\hline 1989 & 5.03 & 1989 & 5.03 & $\mathrm{C}_{2} \mathrm{O}^{*}$ \\
\hline \multirow[t]{2}{*}{1857} & 5.39 & 1857 & 5.39 & $\mathrm{HCO}$ \\
\hline & & 1585 & 6.31 & $?$ \\
\hline \multirow[t]{2}{*}{1562} & 6.40 & & & $\mathrm{C}_{3} \mathrm{O}_{2}^{*}$ \\
\hline & & 1525 & 6.56 & $?$ \\
\hline 1090 & 9.17 & 1090 & 9.17 & $\mathrm{HCO}$ \\
\hline \multirow[t]{3}{*}{960} & 10.42 & & & $?$ \\
\hline & & 832 & 12.02 & $\mathrm{C}_{2} \mathrm{H}_{4} ?$ \\
\hline & & 790 & 12.66 & $?$ \\
\hline \multirow[t]{2}{*}{759} & 13.18 & & & $\mathrm{C}_{2} \mathrm{H}_{2}$ \\
\hline & & 744 & 13.44 & $\mathrm{C}_{2} \mathrm{H}_{2}$ \\
\hline \multirow[t]{2}{*}{660} & & & & $\mathrm{CO}_{2}^{*}$ \\
\hline & & 580 & 17.24 & $?$ \\
\hline 550 & 18.18 & & & $\mathrm{C}_{3} \mathrm{O}_{2}^{*}$ \\
\hline 541 & 18.48 & & & $\mathrm{C}_{3} \mathrm{O}_{2}^{*}$ \\
\hline
\end{tabular}

* Also observed in UV photolysis of pure CO. See Gerakines et al. (1996) and Trottier \& Brooks (2004) and references therein.

Where $\left\langle E_{h v}\right\rangle$ is the average photon energy $\left[\mathrm{eV}\right.$ photon $\left.^{-1}\right], \Phi_{\mathrm{abs}}$ the absorbed photon flux [photons $\mathrm{cm}^{-2} \mathrm{~s}^{-1}$ ], $t$ is photolysis time [s] and $N_{0}$ is the column density of benzene at $t=$ 0 [molecules $\left.\mathrm{cm}^{-2}\right]$. The determination of absorbed doses in UV experiments was previously described by Gerakines et al. (2000) where the authors used optically thick samples and assumed that all photons were absorbed in the sample. Here, we focus on optically thin samples that allow the use of first order reaction kinetics to describe the destruction of benzene. Therefore, we have performed simple actinometry experiments where a layer of solid $\mathrm{O}_{2}$ is accreted onto the sample window before the deposition of a $\mathrm{C}_{6} \mathrm{H}_{6} / \mathrm{Ar}$ mixture. UV photons that enter the oxygen sample layer after passing through the $\mathrm{C}_{6} \mathrm{H}_{6} /$ Ar layer can photolyze the $\mathrm{O}_{2}$ molecules to form the infrared active $\mathrm{O}_{3}$ with a strong band at $1040 \mathrm{~cm}^{-1}$. By monitoring the conversion rate of the infrared inactive $\mathrm{O}_{2}$ to the infrared active $\mathrm{O}_{3}$ molecule during photolysis (see Cottin et al. 2003 , for details) we can calculate the fraction of photons that is absorbed in the $\mathrm{C}_{6} \mathrm{H}_{6} / \mathrm{Ar}$ matrix. We assume a minimal effect on the results from interactions in the boundary layer. For
Table 5. Observed new features after proton and UV irradiation of solid $\mathrm{C}_{6} \mathrm{H}_{6} / \mathrm{CO}_{2}$ (1:20) samples. In Fig. 6 we show the spectra before and after proton bombardment. Features denoted with question marks are broad bands likely due to organic residues.

\begin{tabular}{lllll}
\hline \hline \multicolumn{3}{c}{ Observed transition } & Assignment \\
\multicolumn{3}{c}{$\mathrm{p}^{+}$} & \multicolumn{3}{c}{$\mathrm{UV}$} & \\
$\left(\mathrm{cm}^{-1}\right)$ & $(\mu \mathrm{m})$ & $\left(\mathrm{cm}^{-1}\right)$ & $(\mu \mathrm{m})$ & \\
\hline 3298 & 3.03 & & & substituted $\mathrm{C}_{2} \mathrm{H}_{2}$ \\
3252 & 3.08 & & & $\mathrm{C}_{2} \mathrm{H}_{2}$ \\
2140 & 4.67 & 2140 & 4.67 & $\mathrm{CO}^{*}$ \\
2090 & 4.79 & 2090 & 4.79 & ${ }^{13} \mathrm{CO}^{*}$ \\
2042 & 4.90 & 2042 & 4.90 & $\mathrm{CO}_{3}^{*}$ \\
1880 & 5.32 & & & $\mathrm{CO}_{3}^{*}$ \\
1723 & 5.80 & 1724 & 5.80 & $?$ \\
1692 & 5.91 & & & $?$ \\
1658 & 6.03 & & & $?$ \\
1300 & 7.69 & & & $?$ \\
1175 & 8.51 & & & $?$ \\
1072 & 9.33 & & & $?$ \\
1040 & 9.62 & 1040 & 9.62 & $\mathrm{O}_{3}$ \\
974 & 10.27 & & & $?$ \\
797 & 12.55 & 798 & 12.53 & \\
763 & 13.11 & & & $\mathrm{C}_{2} \mathrm{H}_{2}$ \\
\hline
\end{tabular}

* Also observed in UV photolysis of pure $\mathrm{CO}_{2}$ and $\mathrm{CO}$ solids see Gerakines et al. (1996) and Trottier \& Brooks (2004) and references therein.

the layer thicknesses used in these experiments argon does not absorb UV photons and thus all absorbed photons are absorbed by benzene.

We found that about $25 \%$ of the impinging photons were absorbed in a $1.25 \mu \mathrm{m}$ layer of 1:500 solid $\mathrm{C}_{6} \mathrm{H}_{6} / \mathrm{Ar}$ mixture. Through the Beer law for spectroscopic absorption we can now calculate the UV absorption cross section for benzene isolated in argon and for pure benzene. The Beer law can be written as follows:

$f_{i}=\frac{\Phi}{\Phi_{0}}=\mathrm{e}^{-\beta N_{0}}$

where $\Phi_{0}$ and $\Phi$ are the flux of the UV photons before and after passing through the $\mathrm{C}_{6} \mathrm{H}_{6} /$ Ar sample [photons $\mathrm{cm}^{-2} \mathrm{~s}^{-1}$ ]. The value of $\Phi_{0}$ is known from separate lamp calibration experiments where the $\mathrm{O}_{3}$ formation rate is determined from irradiation of only an $\mathrm{O}_{2}$ sample layer on the substrate (Cottin et al. 2003) while $\Phi$ was obtained from the $\mathrm{O}_{2}$ to $\mathrm{O}_{3}$ conversion rate in experiments described above. The ratio of these two fluxes (the absorptance, $f_{i}$ ) is the fraction of UV photons that is absorbed by benzene in the argon layer. Here, we neglect that the column density is a function of photolysis time and assume it is a constant for the short irradiation timescales considered here. Now, $\beta$ can be regarded as the UV absorption cross section $\left[\mathrm{cm}^{2}\right.$ molecule $\left.{ }^{-1}\right]$ integrated over the bands in the lamp spectrum where $\mathrm{O}_{2}$ photodissociates (see Okabe 1978). Thus, when $\beta$ is known we can calculate the ratio of $\Phi / \Phi_{0}$ for a given column density of absorbing molecules. The total photon 


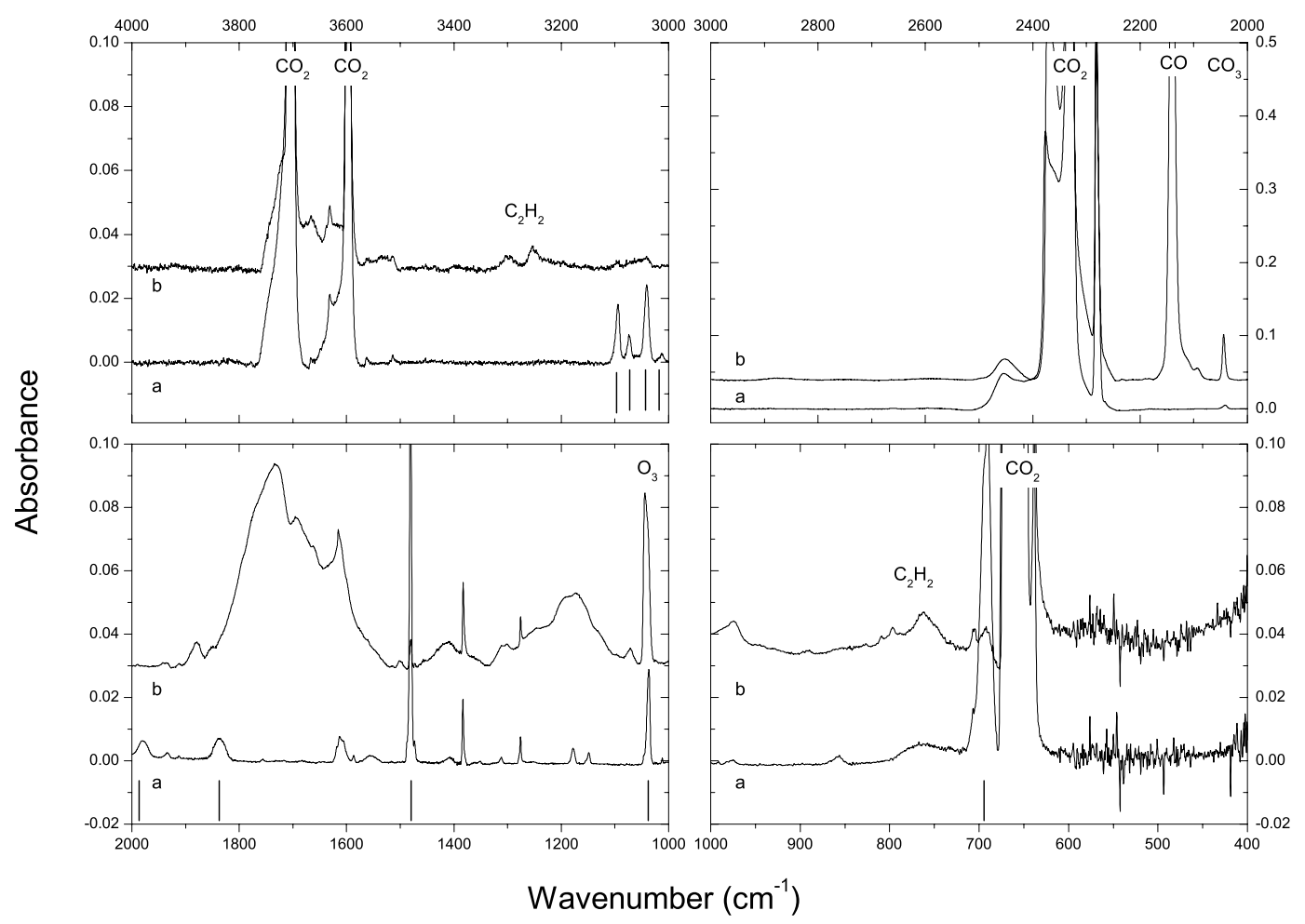

Fig. 6. New features that appeared in solid $\mathrm{C}_{6} \mathrm{H}_{6} / \mathrm{CO}_{2}$ (1:20) after proton irradiation. Trace a) depicts the spectral region before irradiation, while trace b) shows the spectrum after irradiation to a total dose of $\sim 15 \mathrm{eV}$ molecule ${ }^{-1}$. In Table 5 we list the band positions of photoproducts. Benzene features are marked with vertical tick marks. The broad bands that show after proton bombardment between $1800-1600 \mathrm{~cm}^{-1}$ and $1300-1100 \mathrm{~cm}^{-1}$ are possibly due to organic residues that may form from photoproducts.

flux that is absorbed by molecules in the sample $\left(\Phi_{\text {abs }}\right)$ can be expressed as:

$\Phi_{\mathrm{abs}}=\left(1-f_{i}\right) \Phi_{0}$.

For benzene isolated in argon we found $\beta=3.2 \times$ $10^{-16} \mathrm{~cm}^{2}$ molecule ${ }^{-1}$ and for pure benzene $\beta=1.6 \times$ $10^{-17} \mathrm{~cm}^{2}$ molecule ${ }^{-1}$. Although not used in this work, similar experiments on layers of solid (not matrix isolated) $\mathrm{H}_{2} \mathrm{O}$, $\mathrm{CO}$ and $\mathrm{CO}_{2}$ solids yielded $\beta=4.5 \times 10^{-17}, 1.8 \times 10^{-18}$ and $1.1 \times 10^{-18} \mathrm{~cm}^{2}$ molecule ${ }^{-1}$ respectively.

\subsubsection{Proton bombardment}

Absorbed radiation energies per benzene molecule were calculated using the weighted average of the stopping powers for $0.8 \mathrm{MeV}$ protons as described by Moore \& Hudson (1998). The stopping power for $0.8 \mathrm{MeV}$ protons in each experiment was calculated using the SRIM2003 software package by Biersack and Ziegler. For benzene we obtained a stopping power of $307.3 \mathrm{MeV} \mathrm{cm}^{2} \mathrm{~g}^{-1}$. For solid argon we obtained $170.2 \mathrm{MeV} \mathrm{cm}^{2} \mathrm{~g}^{-1}$. When a sample is bombarded with a proton beam with flux $\left[\mathrm{p}^{+} \mathrm{cm}^{-2} \mathrm{~s}^{-1}\right.$ ] for a time $t$ [s] then the dose $D\left[\mathrm{eV}\right.$ molecule $\left.{ }^{-1}\right]$ is given by the product of the weighted average of the stopping powers per proton $\left\langle S_{\mathrm{av}}\right\rangle\left[\mathrm{eV} \mathrm{cm}^{2} \mathrm{~g}^{-1}\right]$, and the fluence divided by the average number of molecules per gram of sample.

$D_{\mathrm{p}^{+}}=\frac{\left\langle M_{\mathrm{w}}\right\rangle\left\langle S_{\mathrm{av}}\right\rangle \Phi_{\mathrm{p}^{+}} t}{\mathrm{~A}_{0}}$ where $\left\langle M_{\mathrm{w}}\right\rangle\left[\mathrm{g}\right.$ mole $\left.{ }^{-1}\right]$ is the weighted average of the molecular weights of all the molecules in the sample mixture, $\Phi_{\mathrm{p}^{+}}$the proton flux, $t$ the irradiation time and $\mathrm{A}_{0}$ Avogadro's constant $\left[\right.$ molecules mole $\left.{ }^{-1}\right]$. The obtained dose applies to a random molecule in the matrix with molecular mass $\left\langle M_{\mathrm{w}}\right\rangle$. Generally, the dose absorbed by the different molecules in a mixture is weighted according to the electron fraction of each component. To obtain the dose absorbed per benzene molecule we substitute the average molecular weight in the sample $\left(\left\langle M_{\mathrm{w}}\right\rangle\right)$, with the molecular weight of benzene $\left(m_{\mathrm{w}}\right)$. The dose absorbed per benzene molecule in the matrix is now expressed in units of $\left[\mathrm{eV}\right.$ molecule $\left.{ }^{-1}\right]$. Here we use the molecular weight of benzene instead of the relative electron abundance since this gives only small errors (much less than $1 \%$ for experiments with argon, and only in the order of $1 \%$ for all other experiments) and simplifies the calculation of the absorbed dose.

\subsection{Destruction rate as a function of absorbed dose}

For UV photolysis in an optically thin sample we assume firstorder reaction kinetics to determine destruction cross sections. This is equivalent to writing $\mathrm{d} N / \mathrm{d} D=-k N$ where $N$ is the sample's column density, $D$ is the energy dose, and $k$ is the rate constant. The destruction rate for photolysis of a molecule can be expressed using Eq. (1) as:

$\frac{\mathrm{d} N}{\mathrm{~d} t}=\frac{\mathrm{d} N}{\mathrm{~d} D_{\mathrm{uv}}} \frac{\mathrm{d} D_{\mathrm{uv}}}{\mathrm{d} t}=\frac{\mathrm{d} N}{\mathrm{~d} D_{\mathrm{uv}}} \frac{E_{h v} \Phi_{\mathrm{abs}}}{N_{0}}=-J_{\mathrm{uv}} N$ 
Table 6. Experimental parameters and destruction $k$ and $J$ values for pure benzene and benzene in different matrices. Numbers in parentheses indicate the exponential power, i.e. $1000=1.0(3)$.

\begin{tabular}{lcccccc}
\hline \hline Sample & $\begin{array}{c}\left\langle S_{\text {av }}\right\rangle \\
\text { eV cm }\end{array}$ & \multicolumn{2}{c}{$N_{0}$} & \multicolumn{2}{c}{$k$} & \multicolumn{2}{c}{$J$} \\
& & molecules cm $\mathrm{g}^{-2}$ & \multicolumn{2}{c}{ molecule $\mathrm{eV}^{-1}$} & \multicolumn{2}{c}{$\mathrm{s}^{-1}$} \\
& & & $\mathrm{p}^{+}$ & $\mathrm{UV}$ & $\mathrm{p}^{+}$ & $\mathrm{UV}$ \\
\hline pure $\mathrm{C}_{6} \mathrm{H}_{6}$ & $3.071(8)$ & $1.5(16)$ & 0.003 & $2.5(-4)$ & $1.5(-5)$ & $2.9(-6)$ \\
$\mathrm{C}_{6} \mathrm{H}_{6} / \mathrm{Ar}$ & $1.725(8)$ & $3.9(15)$ & 0.107 & 0.006 & $2.9(-4)$ & $3.7(-3)$ \\
$\mathrm{C}_{6} \mathrm{H}_{6} / \mathrm{H}_{2} \mathrm{O}$ & $2.830(8)$ & $7.9(15)$ & 0.011 & 0.011 & $5.0(-5)$ & $1.3(-4)$ \\
$\mathrm{C}_{6} \mathrm{H}_{6} / \mathrm{CO}$ & $2.391(8)$ & $2.1(16)$ & 0.109 & 0.024 & $4.2(-4)$ & $2.7(-4)$ \\
$\mathrm{C}_{6} \mathrm{H}_{6} / \mathrm{CO}_{2}$ & $2.441(8)$ & $6.5(15)$ & 0.147 & 0.039 & $5.7(-4)$ & $4.8(-4)$ \\
\hline
\end{tabular}

with $N$ the column density, $J_{\mathrm{uv}}=\int_{\lambda} \sigma_{\lambda} \Phi_{\lambda} \mathrm{d} \lambda=\sigma_{\mathrm{uv}} \Phi_{0}\left[\mathrm{~s}^{-1}\right]$, with $\sigma_{\mathrm{uv}}$ the integrated UV destruction cross section $\left[\mathrm{cm}^{2}\right.$ molecule $\left.{ }^{-1}\right]$ of the molecule over the lamp spectrum, and $\Phi_{0}$ the integrated UV photon flux (see Cottin et al. 2003, for a detailed discussion on photolysis kinetics). When $k_{\mathrm{uv}}$ is defined as the negative slope in the graph of $\ln \left(N / N_{0}\right)$ against photolysis dose $D_{\text {uv }}$ we obtain:

$J_{\mathrm{uv}}=\frac{k_{\mathrm{uv}} E_{h v} \Phi_{\mathrm{abs}}}{N_{0}}$.

Also since $J=\sigma_{\text {uv }} \Phi_{0}$ with $\Phi_{0}$ the integrated photon flux we can calculate $\sigma_{\mathrm{uv}}$, the UV cross sections for destruction. Similarly, when we assume first order reaction kinetics for the proton bombardment experiments we obtain:

$\frac{\mathrm{d} N}{\mathrm{~d} t}=\frac{\mathrm{d} N}{\mathrm{~d} D_{\mathrm{p}^{+}}} \frac{\mathrm{d} D_{\mathrm{p}^{+}}}{\mathrm{d} t}=\frac{\mathrm{d} N}{\mathrm{~d} D_{\mathrm{p}^{+}}} \frac{m_{\mathrm{w}}\left\langle S_{\mathrm{av}}\right\rangle \Phi_{\mathrm{p}^{+}}}{A_{0}}=-J_{\mathrm{p}^{+}} N$.

Now when $k_{\mathrm{p}^{+}}$is defined as the negative slope in the graph of $\ln \left(N / N_{0}\right)$ against proton radiation dose $D_{\mathrm{p}^{+}}$we obtain:

$J_{\mathrm{p}^{+}}=\frac{k_{\mathrm{p}^{+}} m_{\mathrm{w}}\left\langle S_{\mathrm{av}}\right\rangle \Phi_{\mathrm{p}^{+}}}{\mathrm{A}_{0}}=\sigma_{\mathrm{p}^{+}} \Phi_{\mathrm{p}^{+}}$.

Half-lives [s] are defined as:

$t_{1 / 2}=\frac{\ln 2}{J_{\mathrm{uv}}}, \frac{\ln 2}{J_{\mathrm{p}^{+}}}$

For our UV lamp we found that during the matrix isolation experiments the flux was $\Phi_{0}=4.5 \times 10^{14}$ photons $\mathrm{cm}^{-2} \mathrm{~s}^{-1}$ while during the oxygen rich matrix experiments the flux was reduced to $\Phi_{0}=1.1 \times 10^{14}$ photons $\mathrm{cm}^{-2} \mathrm{~s}^{-1}$. The proton flux was constant at $1.2 \times 10^{11}$ protons $\mathrm{cm}^{-2} \mathrm{~s}^{-1}$.

The proton and UV destruction rates of benzene isolated in argon and pure benzene are shown in Fig. 7. Destruction rates for benzene in $\mathrm{H}_{2} \mathrm{O}, \mathrm{CO}$ and $\mathrm{CO}_{2}$ are shown in Fig. 8 . The obtained $k$ and $J$ values and the cross sections and half lifes are given in Tables 6 and 7. We find that the $k$ values for UV experiments are less than those for proton bombardment experiments, except for the $\mathrm{H}_{2} \mathrm{O}$ experiments. This difference may be due to the changes in optical properties of the ices that accompany photolysis, but not radiolysis (Baratta et al. 2002).
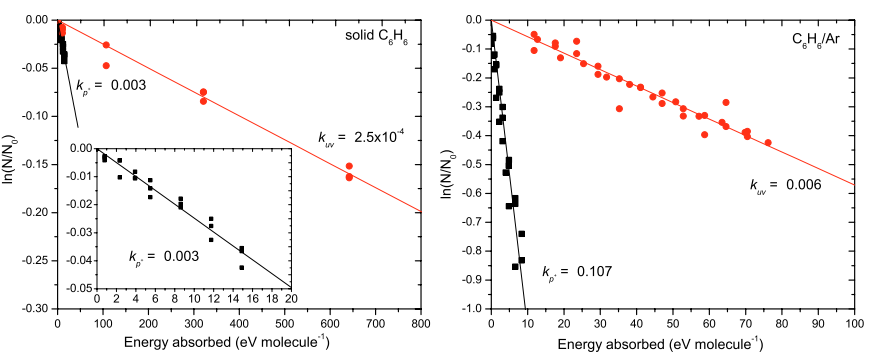

Fig. 7. Destruction of solid benzene (left panel) and benzene isolated in Ar (right panel) as a function of absorbed energy dose $(\bullet=\mathrm{UV}, \mathbf{\square}=$ protons). The negative slope $(k)$ of the plot is related to destruction cross section and half-life through Eqs. (7)-(9).

Table 7. Laboratory measured benzene destruction cross sections and half-lives for astronomically relevant ice mixtures. Numbers in parentheses indicate the exponential power, i.e. $1000=1.0(3)$.

\begin{tabular}{lcccc}
\hline \hline Sample & \multicolumn{2}{c}{$\sigma$} & \multicolumn{2}{c}{$t_{1 / 2}$} \\
& \multicolumn{2}{c}{$\mathrm{cm}^{2}$} & \multicolumn{2}{c}{$\mathrm{s}$} \\
& $\mathrm{p}^{+}$ & $\mathrm{UV}$ & $\mathrm{p}^{+}$ & $\mathrm{UV}$ \\
\hline pure $\mathrm{C}_{6} \mathrm{H}_{6}$ & $1.19(-16)$ & $2.64(-20)$ & $4.72(4)$ & $2.4(5)$ \\
$\mathrm{C}_{6} \mathrm{H}_{6} / \mathrm{Ar}$ & $2.39(-15)$ & $8.13(-18)$ & $2.36(3)$ & $1.9(2)$ \\
$\mathrm{C}_{6} \mathrm{H}_{6} / \mathrm{H}_{2} \mathrm{O}$ & $4.03(-16)$ & $1.23(-18)$ & $1.40(4)$ & $5.1(3)$ \\
$\mathrm{C}_{6} \mathrm{H}_{6} / \mathrm{CO}$ & $3.38(-15)$ & $2.42(-18)$ & $1.67(3)$ & $2.6(3)$ \\
$\mathrm{C}_{6} \mathrm{H}_{6} / \mathrm{CO}_{2}$ & $4.65(-15)$ & $4.39(-18)$ & $1.21(3)$ & $1.4(3)$ \\
\hline
\end{tabular}

\section{Astrophysical implications}

Destruction of benzene by proton bombardment in cold argon matrices is in the same range as for benzene locked up in $\mathrm{CO}$ or $\mathrm{CO}_{2}$ samples but some 20 times faster than for proton bombardment of solid benzene and 6 times faster for benzene in $\mathrm{H}_{2} \mathrm{O}$.

Cold, matrix isolated benzene is destroyed some 1300 times faster by UV photons than solid benzene. UV destruction of benzene in $\mathrm{CO}_{2}$ is slightly faster than for benzene in $\mathrm{H}_{2} \mathrm{O}$ or $\mathrm{CO}$ ices but some 7 times slower than benzene isolated in an Ar matrix.

When we compare the effectiveness for destruction between each processing method we focus on the destruction 

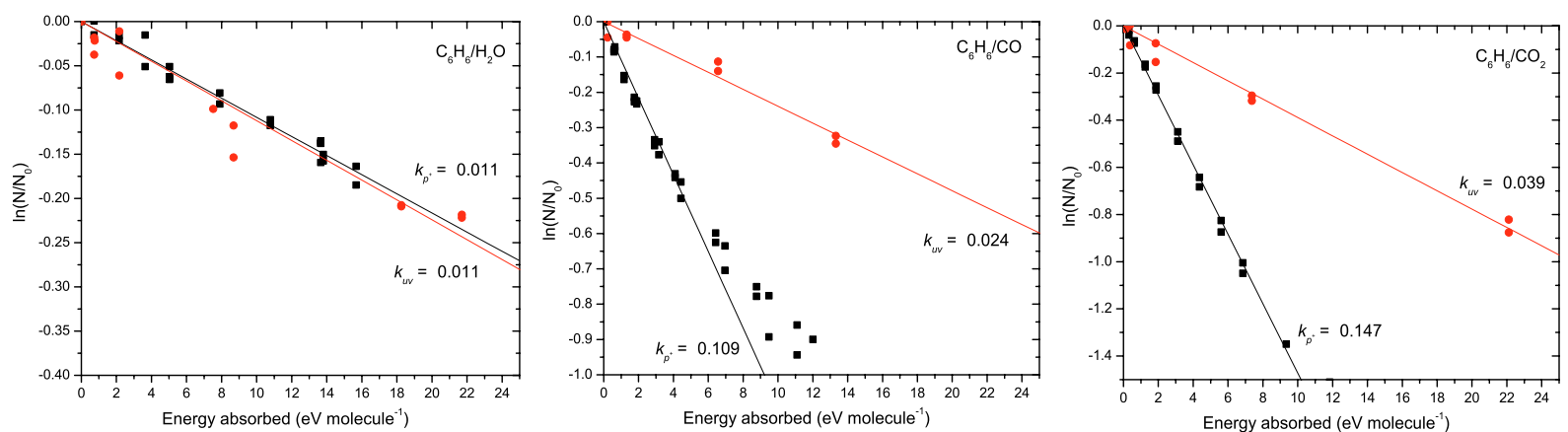

Fig. 8. Destruction of benzene in: water ice (1:5, left panel), in $\mathrm{CO}(1: 30$, middle panel $)$ and in $\mathrm{CO}_{2}(1: 20$, right panel) ices as a function of absorbed energy dose $(\bullet=\mathrm{UV}, \boldsymbol{\square}=$ protons $)$. The negative slope $(k)$ of the plot is related to destruction cross section and half-life through Eqs. (7)-(9).

cross sections and find that proton bombardment of solid benzene is 4500 times more efficient than the UV photolysis of solid benzene. For matrix isolated benzene in argon we find that the destruction cross section of benzene by proton bombardment is some 300 times higher than for UV photolysis. Benzene locked up in solid $\mathrm{CO}$ or $\mathrm{CO}_{2}$ is destroyed some 1000 times more efficiently by proton bombardment while benzene locked up in $\mathrm{H}_{2} \mathrm{O}$ ice is destroyed 400 times more efficiently by proton bombardment. Apparently, the energy transfer in proton bombardment experiments is much more efficient which results in a higher benzene destruction rate.

Previous photolysis studies by Yokoyama et al. (1990) found a destruction cross section for gas phase benzene in the order of $1-5 \times 10^{-17} \mathrm{~cm}^{2}$. Those experiments were not measured in an astrophysical context (low temperatures and VUV). Our experiments are aimed at simulating interstellar conditions with low temperatures. Consequently, an inert, low perturbing argon matrix was used. As we will show in this section we find destruction cross sections 1.5-7 times lower in argon matrices. Perturbations that are expected from the matrix, such as dissipation of the delivered energy, may be responsible for differences compared to gas phase data and therefore, our matrix isolation experiments provide a lower limit for benzene destruction in interstellar environments. However, we shall use the destruction cross section derived from matrix isolated benzene experiments to extrapolate to gas phase benzene in interstellar environments. When hereafter gas phase benzene is mentioned, it refers to the destruction cross section of matrix isolated benzene.

We can now deduce half-lives for the benzene molecule in astronomical environments. Assuming first-order behavior over the entire range of photolytic and protolytic decay, we can define the astronomical half-life as:

$t_{1 / 2}^{*}=\frac{\ln 2}{\Phi^{*} \sigma}$

where $\sigma$ is the laboratory destruction cross section and $\Phi^{*}$ the interstellar UV photon or proton flux.

For the destruction rate of benzene in cold dense molecular clouds we use a UV flux of $10^{3}$ photons $\mathrm{cm}^{-2} \mathrm{~s}^{-1}$ (Prasad \& Tarafdar 1983) and a proton flux of 1 proton $\mathrm{cm}^{-2} \mathrm{~s}^{-1}>1 \mathrm{MeV}$. The destruction rate of benzene in diffuse interstellar clouds is based on a UV flux of $10^{8}$ photons $\mathrm{cm}^{-2} \mathrm{~s}^{-1}$ (Mathis et al. 1983)
Table 8. Interstellar half-lives [year] for benzene. No ices are expected in diffuse clouds and values were not calculated.

\begin{tabular}{lcccc}
\hline \hline & \multicolumn{2}{c}{$t_{1 / 2} \mathrm{p}^{+}$} & \multicolumn{2}{c}{$t_{1 / 2} \mathrm{UV}$} \\
& \multicolumn{2}{c}{ year } & \multicolumn{2}{c}{ year } \\
& dense & diffuse & dense & diffuse \\
\hline pure $\mathrm{C}_{6} \mathrm{H}_{6}$ & $1.8(8)$ & $1.8(7)$ & $8.3(8)$ & $8.3(3)$ \\
$\mathrm{C}_{6} \mathrm{H}_{6} / \mathrm{Ar}$ & $9.2(6)$ & $9.2(5)$ & $2.7(6)$ & $2.7(1)$ \\
$\mathrm{C}_{6} \mathrm{H}_{6} / \mathrm{H}_{2} \mathrm{O}$ & $5.5(7)$ & - & $1.8(7)$ & - \\
$\mathrm{C}_{6} \mathrm{H}_{6} / \mathrm{CO}$ & $6.5(6)$ & - & $9.1(6)$ & - \\
$\mathrm{C}_{6} \mathrm{H}_{6} / \mathrm{CO}_{2}$ & $4.7(6)$ & - & $5.0(6)$ & - \\
\hline
\end{tabular}

and a galactic cosmic ray flux of 10 protons $\mathrm{cm}^{-2} \mathrm{~s}^{-1}>1 \mathrm{MeV}$ (Moore et al. 2001). In the solar system at $1 \mathrm{AU}$ the photon flux from the sun $(>6 \mathrm{eV})$ is $3.0 \times 10^{13}$ photons $\mathrm{cm}^{-2} \mathrm{~s}^{-1}$ while the proton flux is dominated by solar flares that generate an average flux of $10^{10}$ protons $\mathrm{cm}^{-2}$ per year.

Figure 9 shows a summary of our results for all radiation environments. The figure shows the half-life (in years) as a function of the proton and photon flux. Different astronomical environments are indicated in the figure.

In Table 8 we give the half-life for benzene in diffuse and dense clouds. The half-life of benzene $3 \times 10^{6}$ years. This is longer than the estimated average lifetime for dense clouds (Elmegreen 2000). Based on the experiments on solid $\mathrm{C}_{6} \mathrm{H}_{6}$ the half-life for a solid layer of benzene that is exposed to the dense cloud UV field is $\sim 8 \times 10^{8}$ years while the half-life for a solid benzene layer due to proton bombardment is $\sim 2 \times 10^{8}$ years. This is well above the average lifetime of a dense molecular cloud. Destruction time scales of proton bombardment and UV photolysis of benzene in dense clouds are in the same range and we expect benzene to survive dense cloud environments.

As soon as the photon flux increases, such as in diffuse cloud environments, we find that benzene may only survive when sufficiently shielded against UV. The half-life of gas phase benzene due to UV photolysis in diffuse clouds is 27 years, as derived from the matrix isolated $\mathrm{C}_{6} \mathrm{H}_{6} / \mathrm{Ar}$ experiments. The proton flux in diffuse interstellar clouds is sufficient to destroy $50 \%$ of gas phase benzene in $\sim 9 \times 10^{5}$ years. For solid benzene the high energy proton flux is only sufficient 

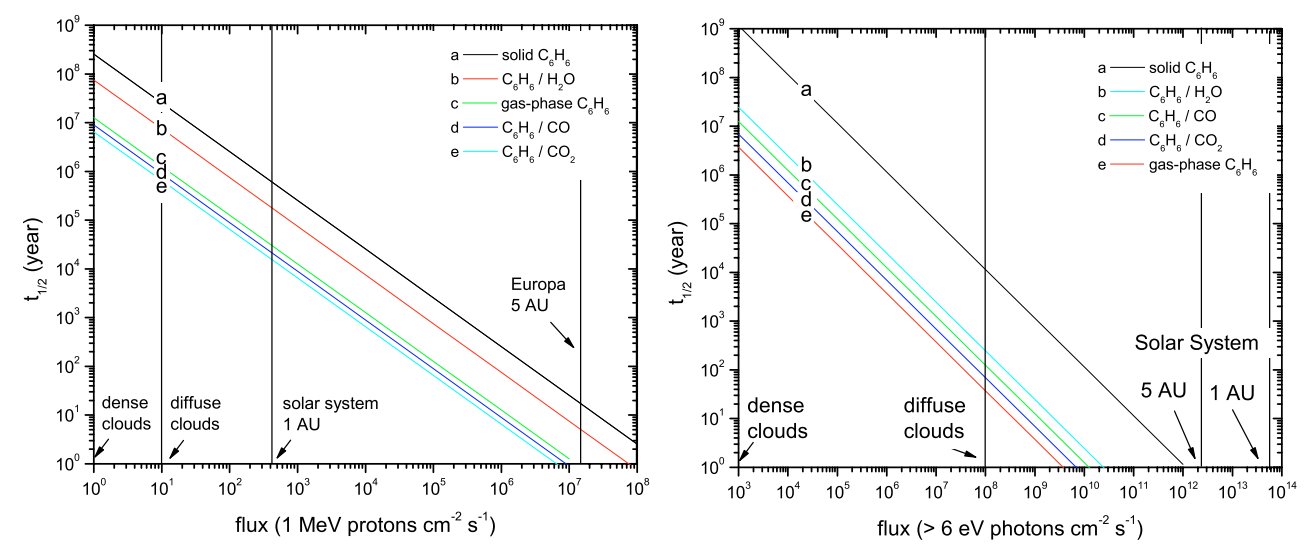

Fig. 9. Interstellar half-lives (see Eq. (10)) derived from laboratory $\mathrm{C}_{6} \mathrm{H}_{6} / \mathrm{Ar}$ and solid pure benzene experiments and for benzene embedded in solid $\mathrm{H}_{2} \mathrm{O}, \mathrm{CO}$ and $\mathrm{CO}_{2}$ as a function of interstellar proton and photon flux. Half-lives in the left panel are given for proton fluxes and in the right panel for photon fluxes.

to destroy $50 \%$ of solid benzene in $\sim 2 \times 10^{7}$ years. Due to the low gas density in diffuse interstellar clouds, no ice layers are expected to cover the dust (Greenberg 1971; Mathis et al. 1983). The UV flux in diffuse interstellar clouds is $10^{8}$ photons $\mathrm{cm}^{-2} \mathrm{~s}^{-1}$ (Mathis et al. 1983) and if we assume that icy grains at the boundary layers to dense clouds exist, typical time scales for the destruction of $50 \%$ of the initial column density are in the order of 100 years for photolysis of benzene in solid $\mathrm{H}_{2} \mathrm{O}$, $\mathrm{CO}$ and $\mathrm{CO}_{2}$, while in the order of $1 \times 10^{6}$ years for radiolysis. Even if benzene is locked up in a solid, time scales for destruction by UV photons are much shorter than the life time of such layers in more diffuse media. We conclude that benzene cannot survive the conditions in the diffuse interstellar medium.

In the solar system at $1 \mathrm{AU}$ from the sun, benzene exposed to the solar UV field has a half-life of $\sim 3 \times 10^{3} \mathrm{~s}$ and solid benzene $\sim 9 \times 10^{5} \mathrm{~s}$. When we scale the solar UV flux at $1 \mathrm{AU}$ to the vicinity of Jupiter (5 AU) we find a flux of $1.2 \times$ $10^{12}$ photons $\mathrm{cm}^{-2} \mathrm{~s}^{-1}$ and can estimate residence times for benzene on icy moons. Destruction time scale for UV photolysis of benzene in water ice now becomes $\sim 5 \times 10^{5} \mathrm{~s}$ and for gas phase benzene $\sim 7 \times 10^{4} \mathrm{~s}$. The $0.8 \mathrm{MeV}$ magnetospheric proton flux at Europa has been estimated by Cooper et al. (2001) who obtained a proton flux of $1.5 \times 10^{7}$ protons $\mathrm{cm}^{-2} \mathrm{~s}^{-1}$. The destruction time scale of benzene locked up in $\mathrm{H}_{2} \mathrm{O}$ ice due to protons on Europa becomes in the order of 4 years and 0.6 years for gas phase benzene. If these fluxes are realistic and if any benzene is delivered to the surface of Europa by comets or volcanism, ions and photons would rapidly destroy it.

\section{Conclusions}

We have measured the stability of solid, matrix isolated and iceembedded benzene against proton bombardment and UV photons. From our matrix isolation experiments we conclude that benzene is about 300 times more efficiently destroyed by proton bombardment than by UV photolysis per absorbed proton or photon. This indicates a more efficient energy transfer during radiolysis. Destruction of benzene leads to fragments of dehydrogenated benzene, methylacetylene and acetylene (and acetylene aggregates) that can be monitored by infrared spectroscopy.

Benzene is likely to survive in the dense parts of circumstellar envelopes but only in a very finite region where UV photons are attenuated. In the diffuse interstellar medium gas phase benzene has a very short half-life of 27 years. Therefore, in order to survive the diffuse interstellar medium conditions, benzene has to be converted into PAH molecules which are more stable against the harsh environment of high UV flux. In dense interstellar clouds benzene could survive in the gas phase or embedded in interstellar grain mantles for a period comparable to the lifetime of the cloud. In the solar system benzene will be rapidly destroyed even when embedded in the icy surface of outer solar system objects.

We conclude that benzene could be available for aromatic chemistry when sufficiently shielded in circumstellar envelopes from protons and UV photons and in dense clouds on the surface of interstellar icy grains.

Acknowledgements. We would like to thank the anonymous referees for their critical reading of the paper and for their suggestions to describe the results in identical units that allow a straightforward comparison that further supported our conclusions. This research was performed under SRON program MG-049, NWO-VI 016.023.003 and supported by NASA's SARA and Planetary Atmospheres Programs. The authors thank T. Millar for discussion.

\section{References}

Baratta, G. A., Leto, G., \& Palumbo, M. E. 2002, A\&A, 384, 343

Biersack, J. P., \& Haggmark, L. 1980, Nucl. Instr. Meth. Phys. Res., 174,257

Brown, K. G., \& Person, W. B. 1978, Spectrochim. Acta, 34, 15

Cernicharo, J., Heras, A. M., Tielens, A. G. G. M., et al. 2001, ApJ, 546, L123

Cherchneff, I., Barker, J. R., \& Tielens, A. G. G. M. 1992, ApJ, 401, 269 
Cooper, J. F., Johnson, R. E., Mauk, B. H., Garrett, H. B., \& Gehrels, N. 2001, Icarus, 149, 133

Cottin, H., Moore, M. H., \& Bénilan, Y. 2003, ApJ, 590, 874

Dartois, E., Muñoz Caro, G. M., Deboffle, D., \& d'Hendecourt, L. 2004, A\&A, 423, L33

Ehrenfreund, P., Fraser, H. J., Blum, J., et al. 2003, PlanSS, 51, 473

Elmegreen, B. G. 2000, ApJ, 530, 277

Frenklach, M., \& Feigelson, E. D. 1989, ApJ, 341, 372

George, L., Sanchez-Garćia, E., \& Sander, W. 2003, J. Phys. Chem. A, 107, 6850

Gerakines, P. A., Moore, M. H., \& Hudson, R. L. 2000, A\&A, 357, 793

Gerakines, P. A., Schutte, W. A., \& Ehrenfreund, P. 1996, A\&A, 312, 289

Gibb, E. L., Whittet, D. C. B., Boogert, A. C. A., \& Tielens, A. G. G. M. 2004, ApJS, 151, 35

Greenberg, J. M. 1971, A\&A, 12, 240

Greenberg, J. M., Gillette, J. S., Muñoz Caro, G. M., et al. 2000, ApJ, 531, L71

Herbig, G. H. 1995, ARA\&A, 33, 1974

Hudgins, D. M., \& Allamandola, L. J. 1999a, ApJ, 516, L41

Hudgins, D. M., \& Allamandola, L. J. 1999b, ApJ, 513, L69

Hudson, R. L., \& Moore, M. H. 1995, Rad. Phys. Chem., 45, 779

Jacox, M. E., \& Milligan, D. E. 1974, Chem. Phys., 4, 45

Johnson, R. E. 1996, BAAS, 28, 1072

Mathis, J. S., Mezger, P. G., \& Panagia, N. 1983, A\&A, 128, 212

Moore, M. H., \& Hudson, R. L. 1998, Icarus, 135, 518
Moore, M. H., \& Hudson, R. L. 2000, Icarus, 145, 282

Moore, M. H., Hudson, R. L., \& Gerakines, P. A. 2001, Spectrochim. Acta, 57, 843

Northcliffe, L. C., \& Shilling, R. F. 1970, Nucl. Data Tables, 7, 233

Okabe, H. 1978, Photochemistry of small molecules, A WileyInterscience Publication (New York: Wiley)

Peeters, Z., Botta, O., Charnley, S. B., Ruiterkamp, R., \& Ehrenfreund, P. 2003, ApJ, 593, L129

Pendleton, Y. J., \& Allamandola, L. J. 2002, ApJS, 138, 75

Prasad, S. S., \& Tarafdar, S. P. 1983, ApJ, 267, 603

Roser, J. E., Vidali, G., Manicò, G., \& Pirronello, V. 2001, ApJ, 555, L61

Sandford, S. A., Bernstein, M. P., Allamandola, L. J., Goorvitch, D., \& Teixeira, T. C. V. S. 2001, ApJ, 548, 836

Strazzulla, G., \& Baratta, G. A. 1991, A\&A, 241, 310

Tielens, A. G. G. M., Hony, S., van Kerckhoven, C., \& Peeters, E. 1999, in ESA SP-427: The Universe as Seen by ISO, 767

Trottier, A., \& Brooks, R. L. 2004, ApJ, 612, 1214

Whittet, D. C. B., Schutte, W. A., Tielens, A. G. G. M., et al. 1996, A\&A, 315, L357

Woods, P. M., Millar, T. J., Zijlstra, A. A., \& Herbst, E. 2002, ApJ, 574, L167

Yokoyama, A., Zhao, X., Hintsa, E. J., Continetti, R. E., \& Lee, Y. T. 1990, J. Chem. Phys., 92, 4222

Ziegler, J. F. 1977, The Stopping and Range of Ions in Matter: Vols. 2-6 (Pergamon Press) 